\title{
A selected pre-amplification strategy for genetic analysis using limited DNA targets
}

\author{
Peng Xia ${ }^{1,2}$, Ramin Radpour ${ }^{1}$, Corina Kohler ${ }^{1}$, \\ Cheng Xue Dang ${ }^{2}$, Alex Xiu Cheng Fan', \\ Wolfgang Holzgreve ${ }^{3}$ and Xiao Yan Zhong ${ }^{1, *}$ \\ ${ }^{1}$ Laboratory for Prenatal Medicine and Gynecologic \\ Oncology, Women's Hospital/Department of \\ Biomedicine, University of Basel, Basel, Switzerland \\ ${ }^{2}$ Department of Oncology Surgery, First Affiliated \\ Hospital of Medical College, Xi'An Jiaotong \\ University, Xi'An, China \\ ${ }^{3}$ University Hospital Freiburg, Freiburg, Germany
}

\section{Abstract}

Background: Limited DNA resources or limited DNA targets in predominant backgrounds for genetic tests can lead to misdiagnosis. We developed a strategy to selectively increase the amount of minor targets through a specific pre-amplification procedure.

Methods: We used the model of circulating cell free (ccf) male fetal DNA as a minor target in the predominant maternal plasma DNA to evaluate the strategy. The sex determining region (SRY) locus on the $Y$ chromosome was used to identify ccf fetal DNA, and the human glyceraldehydes-3-phosphate dehydrogenase (GAPDH) gene was used to identify ccf total DNA in maternal plasma. We selectively pre-amplified the minor target SRY locus using the Expand Long Template PCR system and assessed the efficiency of the pre-amplification by real-time PCR, for both SRY and GAPDH, to compare the quantities of pre-amplified fetal DNA with those of maternal total DNA without pre-amplification.

Results: The selected pre-amplification increased the amount of ccf fetal DNA dramatically (Wilcoxon test: $p=0.000$, the fold change $=11,596)$. After selected preamplification, a proportion of $2.19 \%$ of the ccf fetal minor part in the predominant maternal component was changed up to $25,334 \%$. The increased amounts of ccf fetal DNA found with the pre-amplification are not correlated to the amounts found without the procedure $(r=-0.017, p=0.949)$.

Conclusions: This strategy may be useful in genetic analysis with limited DNA resources and limited DNA targets in predominant background molecules. However, this approach is not suitable for quantitative assessments, due to the fact that quantitative imbal-

\footnotetext{
*Corresponding author: Prof. Dr. Xiao Yan Zhong, Laboratory for Prenatal Medicine and Gynecologic Oncology, Women's Hospital/Department of Biomedicine, University of Basel, Hebelstrasse 20, Room Nr. 416, 4031 Basel, Switzerland

Phone: +41-61-265-9224/9595, Fax: +41-61-265-9399,

E-mail: xzhong@uhbs.ch

Received July 23, 2008; accepted November 27, 2008; previously published online February 4, 2009
}

anced amplification was observed as a result of the pre-amplification procedure.

Clin Chem Lab Med 2009;47:288-93.

Keywords: genetic analysis; limited DNA resources; limited DNA target; pre-amplification; quantitative real-time PCR.

\section{Introduction}

Genetic analysis using limited DNA resources, or limited DNA targets in predominant backgrounds, can be encountered in many fields of life science (1-3). For pre-implantation genetic diagnosis, only single human blastomeres, or first polar body, can be offered for further analysis $(4,5)$. In forensic medicine, the samples obtained are often damaged or degraded (6). Fine needle aspiration biopsies are minor surgical procedures for which patient's specimens for diagnosis are obtained (7). However, insufficient material acquired through these procedures can lead to difficulty in obtaining definitive conclusions.

Recently, the discovery of tissue-derived cell free and cellular DNA in circulation offers new diagnostic possibilities in two crucial areas - prenatal genetic diagnosis (8) and cancer detection (9).

In prenatal medicine, fetal cells and cell free fetal DNA in maternal blood during pregnancy are potential sources of fetal genetic material for non-invasive prenatal diagnosis $(10,11)$. However, low numbers of fetal cells in predominant maternal blood cells (12) and low concentrations of cell free fetal DNA in earlier gestational ages have limited their use in clinical practice (13).

In the cancer field, many researchers have attempted to establish molecular and immunological methods for the detection of individual metastatic epithelial cancer cells in peripheral blood and bone marrow (14-16). However, a human eukaryotic cell containing only one or two copies of each gene has limited the sensitivity of using genetic alterations as markers on the DNA level to identify single tumorderived cellular and cell free DNA in circulation with predominant DNA from blood cells.

A strategy of whole genome amplification (WGA) has been developed to amplify whole genome DNA for the purpose of increasing the quantity of DNA molecules (17). However, on the one hand, false allele generation and imbalance resulting from varying specificity, sensitivity, and preferential amplification of alleles can lead to misdiagnosis $(18,19)$. On the other hand, WGA may not be suitable for the detection of rare targets in a predominant background, such as rare fetal cells in maternal blood (12), as pref- 
erential amplification of background molecules will make the identification of rare targets more difficult.

In this study, we developed a strategy to pre-amplify targets selectively according to the aims of genetic analysis. We used the model of cell free male fetal DNA in maternal plasma DNA to evaluate the strategy. The sex determining region (SRY) locus on the $Y$ chromosome was used to identify fetal DNA, and the human glyceraldehyde-3-phosphate dehydrogenase (GAPDH) gene was used to identify total circulating cell free (ccf) plasma DNA, almost representing the maternal part (12). Using the Expand Long Template (ELT) PCR kit (Roche Diagnostics $\mathrm{GmbH}$, Mannheim, Germany), we selectively pre-amplified only the SRY locus and assessed the efficiency of the pre-amplification by real-time PCR, for both SRY and GAPDH, in order to compare the quantities of pre-amplified fetal DNA with those of maternal total DNA without pre-amplification.

\section{Materials and methods}

This study was performed in the laboratory of Prenatal Medicine and Gynecologic Oncology at the University Women's Hospital and Department of BioMedicine, University of Basel, Basel, Switzerland. The study was approved by the local Ethical Institutional Review Board and informed consent was obtained from all subjects. A total of 17 plasma samples were collected from pregnant women in the second trimester with single male fetuses at an average of 21 gestational weeks. Fetal gender was obtained by ultrasound and confirmed after delivery.

Cell free DNA was extracted from $400 \mu \mathrm{L}$ plasma using the QIAmp DNA Mini Kit (QIAGEN GmbH, Hilden, Germany), in a final elution volume of $100 \mu \mathrm{L}$, according to the manufacturer's protocol.

\section{Expand Long Template PCR}

The ELT PCR kit (Roche Diagnostics $\mathrm{GmbH}$ ) was used to preamplify the SRY locus, the rare fetal part in maternal plasma, according to the manufacturer's instructions. For each reaction, we used $5 \mu \mathrm{L}$ of DNA templates, $10 \mu \mathrm{M}$ of SRY primers (forward primer: 5'-TCC TCA AAA GAA ACC GTG CAT-3'; reverse primer: 5'-AGA TTA ATG GTT GCT AAG GAC TGG AT-3'), and $250 \mu \mathrm{M}$ of each dNTP (Roche Diagnostics $\mathrm{GmbH}$ ). ELT enzyme and PCR buffers were used in a final volume of $25 \mu \mathrm{L}$ and PCR was performed using a Mastercycler Gradient (Eppendorf, Basel, Switzerland). The total PCR cycling profile was as follows: an initial 2 min denaturation at $92^{\circ} \mathrm{C}$; with the first 10 cycles consisting of a 10 -s step at $92^{\circ} \mathrm{C}$, a 30 -s step at $56^{\circ} \mathrm{C}$, and a 20 -min step at $68^{\circ} \mathrm{C}$ followed by another 25 cycles consisting of a 15 -s step at $92^{\circ} \mathrm{C}$, a $0.5-\mathrm{min}$ step at $56^{\circ} \mathrm{C}$, and a 20 -min step at $68^{\circ} \mathrm{C}$ plus a 20 -s increment for each cycle; and a final extension step of $7 \mathrm{~min}$ at $68^{\circ} \mathrm{C}$.

\section{Real-time PCR}

The quantities of SRY locus (indicating the cell free fetal DNA), with and without the ELT PCR procedure, and the quantity of GAPDH sequences (indicating the cell free maternal background DNA) from the 17 samples were assessed using the $A B I$ PRISM 7000 Sequence Detection System (Applied Biosystems, Foster City, CA, USA). Extracted DNA
(5 $\mu \mathrm{L}$ ) without the ELT PCR procedure for SRY and GAPDH quantifications, and $5 \mu \mathrm{L}$ of 1-10 diluted ELT PCR products, after the ELT PCR procedure for SRY quantification, were used as the templates for real-time PCR.

The above-mentioned primers for SRY were reused, and the probe for SRY was 5' (VIC) TCC CCA CAA CCT CTT (MGB) $3^{\prime}$.

The primers and the probe for GAPDH were as follows:

Forward primer: 5'-CCCCACACACATGCACTTACC-3', Reverse primer: 5'-CCTAGTCCCAGGGCTTTGATT-3', and Probe: 5'-MGB-TAGGAAGGACAGGCAAC-FAM-3'.

For the PCR assay, we used a reaction volume of $25 \mu \mathrm{L}$, containing $5 \mu \mathrm{L}$ of template, primers at a concentration of $300 \mathrm{nM}$, a probe at $200 \mathrm{nM}$, and $12.5 \mu \mathrm{L}$ of $2 \times$ TaqMan $^{\circledR}$ Master Mix (Applied Biosystems, Branchburg, NJ, USA). Each sample was measured in duplicate.

The reaction was performed at the following conditions: a first denaturation step at $95^{\circ} \mathrm{C}$ for $10 \mathrm{~min}$, and 40 cycles of $1 \mathrm{~min}$ at $60^{\circ} \mathrm{C}$, followed by $15 \mathrm{~s}$ at $95^{\circ} \mathrm{C}(12)$.

\section{Data collection}

We obtained the threshold cycle $(\mathrm{Ct})$ values output from the ABI Prism 7000 software. The quantities of SRY and GAPDH were calculated using standard dilution curves generated from a known concentration of a male human genomic DNA, ranging from $3.125 \times 10^{4}$ to $10 \mathrm{pg} / \mu \mathrm{L}$ (including 31,250, 6250, $1250,250,50$, and $10 \mathrm{pg} / \mu \mathrm{L})$. The results were expressed as genome-equivalent (GE) per $\mathrm{mL}$ of plasma by using the conversion factor of $6.6 \mathrm{pg}$ of DNA per cell (20). The fold change of SRY, with and without the ELT PCR procedure, was estimated using a simple equation: mean-sRY with ELT/ mean-sRY without ELT. The proportion of fetal SRY in the total GAPDH was obtained using a similar equation: mean-sRY/ mean-GAPDH $\times 100 \%$ ).

\section{Statistical analysis}

The data analysis was performed using SPSS software (Statistical Software Package for Windows, v15.0, SPSS Inc., Chicago, IL, USA). The Shapiro-Wilk test and the Kolmogorov-Smirnov test were used to analyze the normality. The two tests showed that our dataset was not normally distributed $(p=0.000 / 0.000$ with the Shapiro-Wilk test, and $p=0.000 / 0.001$ with the Kolmogorov-Smirnov test for the SRY assay and the GAPDH assay, respectively). The Wilcoxon test was used to compare the significance of quantities with and without the ELT PCR procedure, and the Spearman test was applied to investigate the correlations between SRY quantities with and without the ELT PCR procedure, as well as between SRY and GAPDH quantities.

\section{Results}

The quantities of ccf fetal DNA (SRY) and ccf maternal DNA (GAPDH) are given in Table 1 as mean, median, range, and fold change. The correlation analyses are also available in Table 1.

Our data show that without the ELT PCR procedure, ccf fetal SRY DNA is present in maternal plasma with a mean of $150 \mathrm{GE} / \mathrm{mL}$ (range 36-484), and the total ccf GAPDH DNA is present in a higher concentration of $6866 \mathrm{GE} / \mathrm{mL}$ (range 298-43,071). The concentration of the fetal part in the maternal background corre- 
Table 1 Quantification and correlation analysis for GAPDH and SRY assays.

\begin{tabular}{|c|c|c|c|c|}
\hline & $\mathrm{SRY}, \mathrm{GE} / \mathrm{mL}$ & $\mathrm{GAPDH}, \mathrm{GE} / \mathrm{mL}$ & SRY/GAPDH & Correlation \\
\hline Without ELT & $\begin{array}{l}150 \text { (mean) } \\
117 \text { (median) } \\
(36-484)\end{array}$ & $\begin{array}{l}6866 \text { (mean) } \\
3180 \text { (median) } \\
(298-43,071)\end{array}$ & $2.19 \%$ & $\begin{array}{l}r=0.061 \\
p=0.815\end{array}$ \\
\hline With ELT & $\begin{array}{l}1,739,441 \text { (mean) } \\
427,979 \text { (median) } \\
(8231-6,211,450)\end{array}$ & ND & $25,334 \%$ & $\begin{array}{l}r=-0.135 \\
p=0.605\end{array}$ \\
\hline $\begin{array}{l}\text { Fold change } \\
\text { Correlation }\end{array}$ & $\begin{array}{l}11,596 \\
r=-0.017 \\
p=0.949\end{array}$ & $\begin{array}{l}\text { ND } \\
\text { ND }\end{array}$ & $\begin{array}{l}11,568 \\
\text { No }\end{array}$ & $\begin{array}{l}\text { No } \\
\text { No }\end{array}$ \\
\hline
\end{tabular}

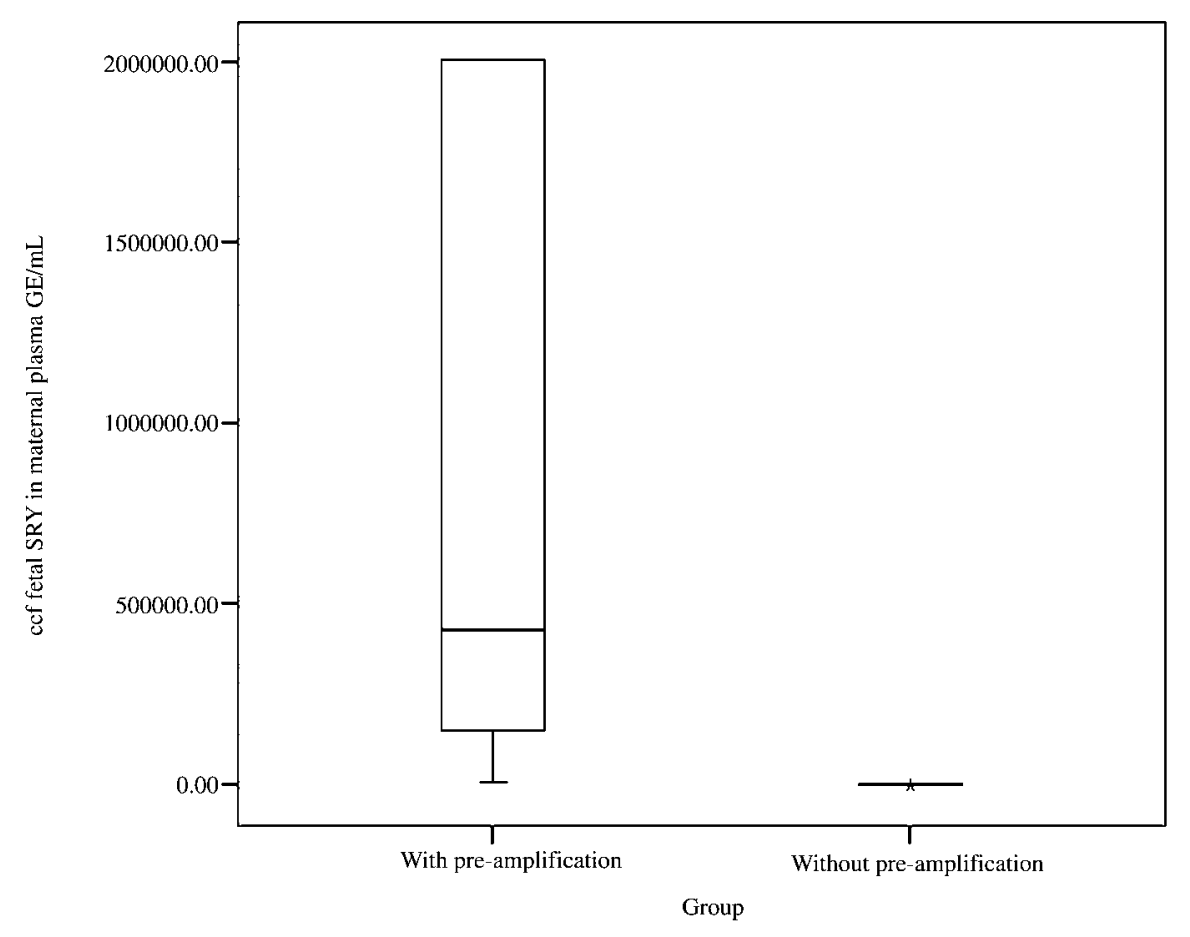

Figure 1 Boxplot: significantly higher amounts of pre-amplified SRY compared to those without pre-amplification.

sponds to $2.19 \%$. With the ELT PCR procedure, the quantities of ccf fetal DNA are dramatically increased with a mean of $1,739,441$ (range 8231-6,211,450) (Wilcoxon test: $p=0.000$ ) (Figure 1). The fold change of pre-amplified SRY, compared to that without preamplification, totals more than 10,000 . The $2.19 \%$ of the minor fetal part in the predominant maternal part was changed up to $25,334 \%$. Also, more than a 10,000 -fold change is obtained. Figure $2 \mathrm{~A}$ shows an example of the increase in fetal SRY after the preamplification in the total GAPDH quantities, and Figure $2 \mathrm{~B}$ shows the comparison of the $\mathrm{Ct}$ value of SRY with and without pre-amplification. The amount of the SRY was increased 2048-fold after selected preamplification. It is an output of a delta $R n$ vs. cycle from the 7000 SDS. The parameter $\mathrm{Ct}$ is defined as the fractional cycle number at which the fluorescence passes the fixed threshold. The high amount of starting SRY after pre-amplification (the earlier lines) shows that the increase takes place sooner in fluorescence than it does in the GAPDH reaction (the later lines).
From the dataset, we did not find any correlation between ccf fetal DNA and ccf maternal DNA. No relationships in the quantification between the treatments with and without ELT PCR procedure were observed, suggesting that the pre-amplification was quantitatively imbalanced (Figure 3).

\section{Discussion}

In this study, we intended to develop a selected preamplification strategy according to pre-amplify-specific targets that may be useful in the cases of using limited DNA resources and limited DNA targets in predominant background molecules. We designed the rare ccf fetal SRY DNA in maternal plasma as the minor target, and the rich ccf maternal GAPDH DNA as the predominant background component. We used the ELT PCR system to specifically pre-amplify the minor fetal SRY sequence separately. The efficiency of the pre-amplification was assessed by real-time PCR. 
A

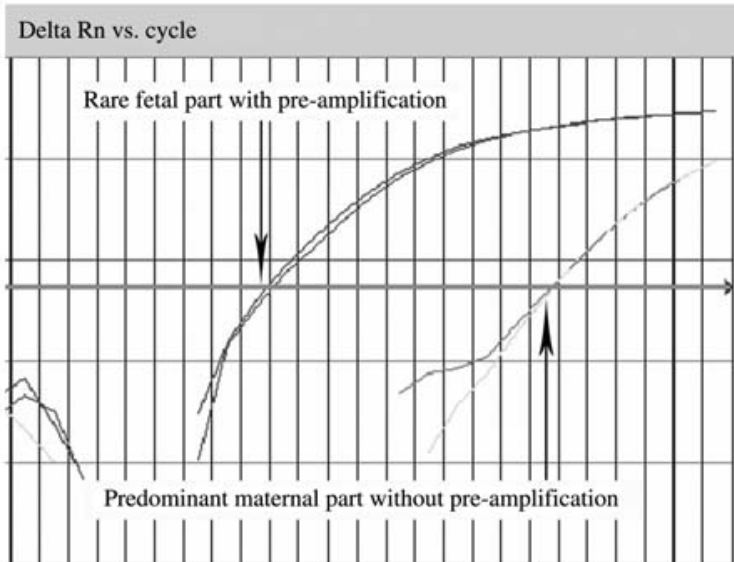

$16171819202122 \quad 2324252627282930313233 \quad 3435 \quad 363738 \quad 3940$

B

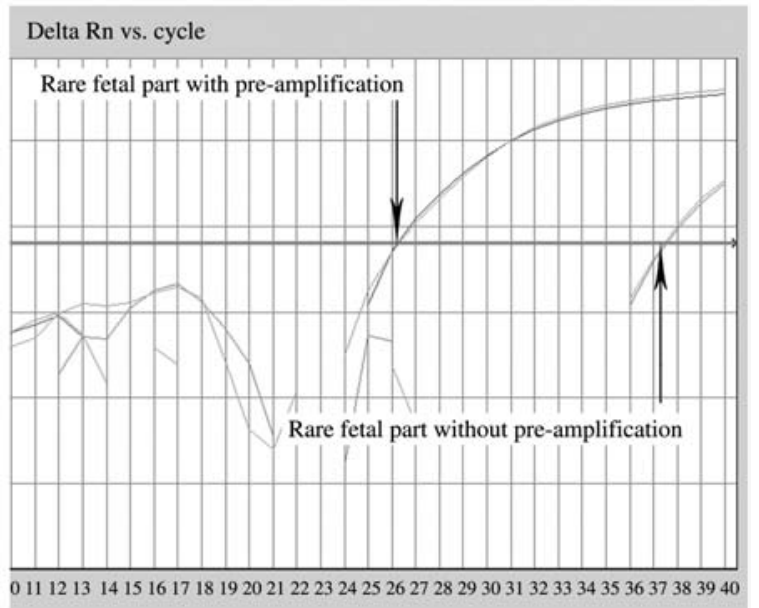

Figure 2 Comparison of PCR efficiency with and without pre-amplification.

(A) The $\mathrm{Ct}$ value of GAPDH (originally representing the predominant maternal component) without pre-amplification and the $\mathrm{Ct}$ value of pre-amplified SRY (originally representing the minor fetal target). The amounts of the minor part were increased dramatically after selected pre-amplification. (B) The comparison of the Ct value of SRY with and without pre-amplification. The amount of the SRY was increased 2048 -fold $\left(2^{\mathrm{ACT}=11}\right)$ after selected pre-amplification.

Our data show that the procedure could increase the minor target dramatically. A fold change of more than 10,000 after pre-amplification could be obtained. We believe that the strategy may be useful in fields, such as single cell genetic diagnosis, testing damaged or degraded DNA samples, and fine needle aspiration biopsies, etc., for which only limited DNA recourses may be available. Compared to the traditional nestedPCR (21), using our pre-amplification, a nested primer pair is not needed. Furthermore, the ELT PCR system used in our study, according to the function of the enzyme included in the system, enables amplification of long templates. Compared to the traditional whole genome pre-amplification, selected pre-amplification according to the aim of the tests may minimize false allele generation and imbalances resulting from varying specificity, sensitivity, and preferential amplification of alleles leading to misdiagnosis.

In our study, the proportional relationship between the minor fetal target and predominant maternal component was changed from $2.19 \%$ up to $25,334 \%$

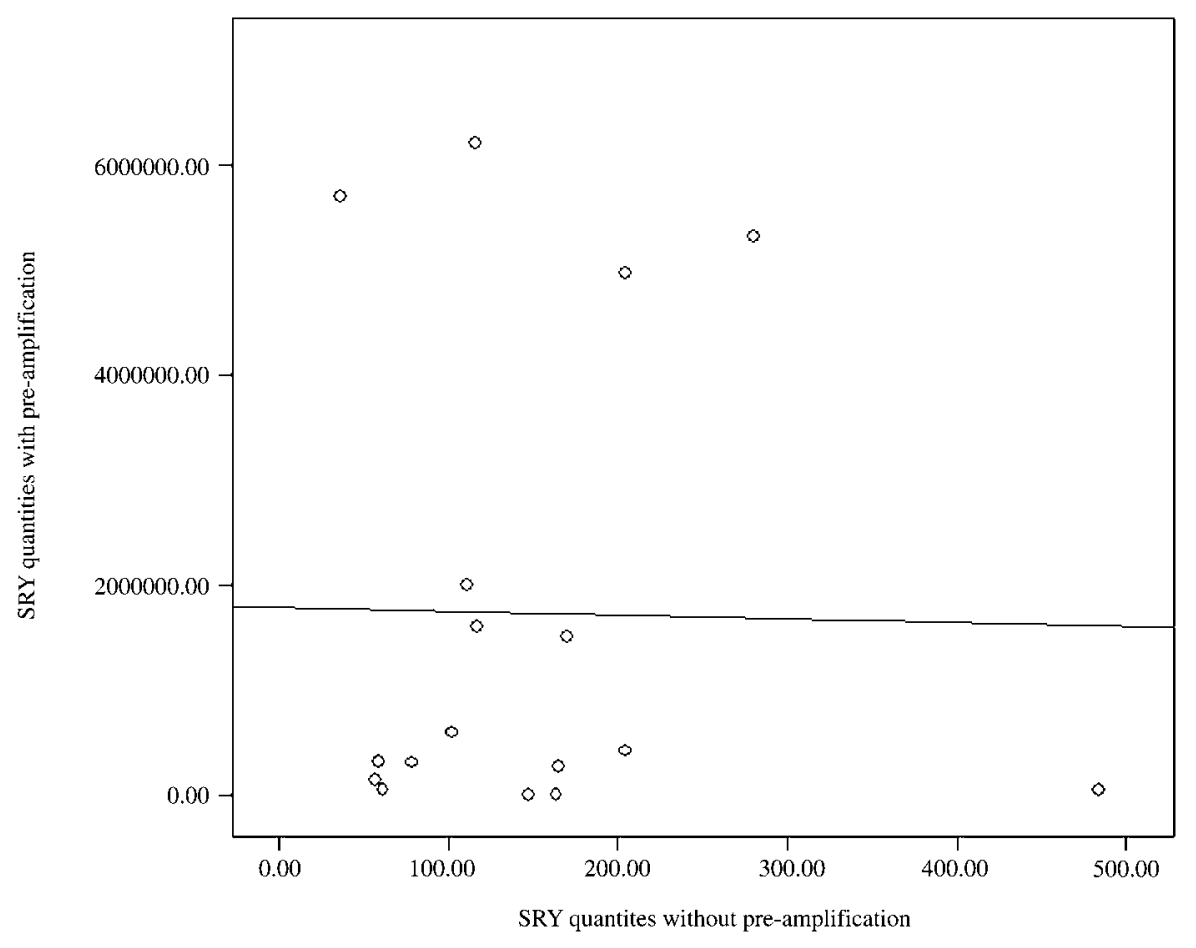

Figure 3 Correlation study between the amounts of SRY, with and without pre-amplification.

The $x$-axis represents the quantities of SRY without pre-amplification. The $y$-axis represents the quantities of SRY with preamplification. Scatter plots show no significant correlation between the amount of SRY with and without pre-amplification $(r=-0.017, p=0.949)$. 
through the pre-amplification, suggesting that the procedure is especially suitable for cases of minor targets in predominant background components, such as fetal cells and ccf fetal DNA in maternal circulation for non-invasive prenatal diagnosis. Non-invasive prenatal diagnosis can be hampered by the limited amounts of fetal genetic materials in maternal circulation, especially in early gestational ages $(13,22)$. Using our strategy, fetal genetic materials in maternal circulation, such as the fetal SRY (for the diagnosis of X-linked diseases) and the fetal RhD in the circulation of RhD positive pregnant women (for the management of RhD-incompatibilities) (10), which are absent from the maternal genome, can be easily selectively pre-amplified, as shown in this study on ccf fetal SRY assay.

For detecting subtle mutations in minor fetal components or minor pathological components, which only differ slightly from the wild-type DNA of interest, a designed peptide nucleic acids clam may be useful to suppress the amplification of the wild-type molecules in the pre-amplification procedures. The clam can be designed to bind to the wild-type allele with very high affinity specifically. In our group, we developed the approach for non-invasive prenatal diagnosis of paternally inherited mutations (23).

In our study, we compared different protocols for the selected pre-amplification using different PCR enzymes and buffers, such as $\operatorname{TaqMan}^{\circledR}$ Master Mix (data not shown). The best results were obtained by using the ELT PCR system. For the pre-amplification, we set up cycling profiles according to the manufacturer's instructions. The cycling profiles could be shortened, if the templates selected for pre-amplification were not long.

We described a strategy to increase the DNA targets selectively by a specific pre-amplification. This strategy was confirmed by a model using ccf fetal SRY as a minor target in the predominant maternal DNA components. This approach is easy to perform, and it may minimize the false allele generation due to using selected pre-amplification, rather than whole genome pre-amplification. It may be useful in genetic analysis with limited DNA resources and limited DNA targets in predominant background molecules, according to the aim of the applications. However, this approach is not suitable for quantitative assessments, due to the fact that quantitative imbalanced amplification resulting from the pre-amplification procedure was observed in our study.

\section{Acknowledgements}

We would like to thank Mrs. Vivian Kiefer her help with the study. We are grateful to Mrs. Regan Geissmann for proofreading the text. This work was supported in part by the Swiss National Science Foundation (320000-119722/1) and the Swiss Cancer League, Krebsliga Beider Basel and Dr. Hans Altschueler Stiftung.

\section{References}

1. Donoso P, Devroey P. PGD for aneuploidy screening: an expensive hoax? Best Pract Res Clin Obstet Gynaecol 2007;21:157-68.

2. Rico A, Ortiz-Barredo A, Ritter E, Murillo J. Genetic characterization of Erwinia amylovora strains by amplified fragment length polymorphism. J Appl Microbiol 2004; 96:302-10.

3. Bianchi DW, Wataganara T, Lapaire O, Tjoa ML, Maron $\mathrm{JL}$, Larrabee PB, et al. Fetal nucleic acids in maternal body fluids: an update. Ann NY Acad Sci 2006;1075: 63-73.

4. Kuliev A, Verlinsky Y. Preimplantation genetic diagnosis: technological advances to improve accuracy and range of applications. Reprod Biomed Online 2008;16:532-8.

5. Bredenoord AL, Pennings G, Smeets HJ, de Wert G. Dealing with uncertainties: ethics of prenatal diagnosis and preimplantation genetic diagnosis to prevent mitochondrial disorders. Hum Reprod Update 2008;14:83-94.

6. Ferri G, Bini C, Ceccardi S, Ingravallo F, Lugaresi F, Pelotti $S$. Minisequencing-based genotyping of Duffy and ABO blood groups for forensic purposes. J Forensic Sci 2006;51:357-60.

7. Noutsias M, Rohde M, Block A, Klippert K, Lettau O, Blunert $K$, et al. Preamplification techniques for real-time RT-PCR analyses of endomyocardial biopsies. BMC Mol Biol 2008;9:3.

8. Norbury G, Norbury CJ. Non-invasive prenatal diagnosis of single gene disorders: how close are we? Semin Fetal Neonatal Med 2008;13:76-83.

9. Zanetti-Dallenbach R, Wight E, Fan AX, Lapaire O, Hahn $S$, Holzgreve W, et al. Positive correlation of cell-free DNA in plasma/serum in patients with malignant and benign breast disease. Anticancer Res 2008;28:921-5.

10. Zhong XY, Holzgreve W, Hahn S. Risk free simultaneous prenatal identification of fetal Rhesus $D$ status and sex by multiplex real-time PCR using cell free fetal DNA in maternal plasma. Swiss Med Wkly 2001;131:70-4.

11. Troeger $C$, Zhong $X Y$, Burgemeister $R$, Minderer $S$, Tercanli S, Holzgreve W, et al. Approximately half of the erythroblasts in maternal blood are of fetal origin. Mol Hum Reprod 1999;5:1162-5.

12. Zhong $X Y$, Holzgreve $W$, Hahn S. Direct quantification of fetal cells in maternal blood by real-time PCR. Prenat Diagn 2006;26:850-4.

13. Li Y, Finning K, Daniels G, Hahn S, Zhong X, Holzgreve W. Noninvasive genotyping fetal Kell blood group (KEL1) using cell-free fetal DNA in maternal plasma by MALDITOF mass spectrometry. Prenat Diagn 2008;28:203-8.

14. Zhong XY, Kaul S, Eichler A, Bastert G. Evaluating GA733-2 mRNA as a marker for the detection of micrometastatic breast cancer in peripheral blood and bone marrow. Arch Gynecol Obstet 1999;263:2-6.

15. Zhong XY, Kaul S, Thompson J, Eichler A, Bastert G. Evaluation of the reverse transcriptase/polymerase chain reaction for carcinoembryonic antigen for the detection of breast cancer dissemination in bone marrow and peripheral blood. J Cancer Res Clin Oncol 1999;125: 669-74.

16. Diel IJ, Solomayer EF, Bastert G. Micrometastatic cells in the bone marrow of patients with breast carcinoma. Radiologe 2000;40:681-7.

17. Bredel M, Bredel C, Juric D, Kim Y, Vogel H, Harsh GR, et al. Amplification of whole tumor genomes and geneby-gene mapping of genomic aberrations from limited sources of fresh-frozen and paraffin-embedded DNA. J Mol Diagn 2005;7:171-82.

18. Schowalter KV, Fredrickson J, Thornhill AR. Efficient isothermal amplification of the entire genome from single cells. Methods Mol Med 2007;132:87-99.

19. Ballantyne KN, van Oorschot RA, Mitchell RJ. Compari- 
son of two whole genome amplification methods for STR genotyping of LCN and degraded DNA samples. Forensic Sci Int 2007;166:35-41.

20. Zhong XY, Hahn S, Steinborn A, Holzgreve W. Quantitative analysis of intact fetal cells in maternal plasma by real-time PCR. Eur J Obstet Gynecol Reprod Biol 2007; 133:20-4.

21. Zhong XY, Holzgreve W, Hahn S. Detection of fetal rhesus $D$ and sex using fetal DNA from maternal plasma by multiplex polymerase chain reaction. Br J Obstet Gynaecol 2000;107:766-9.

22. Zhong $X Y$, Hahn S, Holzgreve W. Prenatal identification of fetal genetic traits. Lancet 2001;357:310-1.

23. Li Y, Di Naro E, Vitucci A, Zimmermann B, Holzgreve W, Hahn S. Detection of paternally inherited fetal point mutations for beta-thalassemia using size-fractionated cell-free DNA in maternal plasma. J Am Med Assoc 2005;293:843-9. 